\title{
Desigualdad rural y conflicto interno armado en Colombia: un círculo vicioso
}

\author{
Rural inequality and armed internal conflict in Colombia: a vicious circle
}

Jorge Iván Gaviria Mesa*, Mónica Lucia Granda Viveros** Juan Diego López Medina**** y Rafael Vargas Cano ${ }^{* * * * *}$

\begin{abstract}
Resumen: La causa fundamental de la violencia en Colombia ha sido la inequitativa repartición de la tierra, que en el escenario mundial es una de las más desiguales. En ese punto, las políticas del Estado colombiano se han movido en dos direcciones: o han sido equivocadas o fueron concebidas de manera dolosa para beneficiar a una minoría, en desmedro del conglomerado campesino. Aquella torpeza, o esta insania, han tenido una clara expresión violenta que tal vez con un desarrollo público a largo plazo pueda ser detenida, a partir de los Acuerdos de la Habana.
\end{abstract}

Palabras clave: desigualdad, tierra, Estado, violencia, acuerdos

\footnotetext{
* Colombiano. Coautor. Abogado, Filósofo y Magíster en Filosofía de la Universidad de Antioquia. Docente de tiempo completo de la Universidad Católica Luis Amigó. Pertenece al Grupo de Investigación Jurídicas y Sociales de la Funlam. Este artículo es un avance de la investigación denominada: "responsabilidad social empresarial en el marco del postacuerdo de paz" desarrollado durante el año 2017 y auspiciado por la Universidad Católica Luis Amigó e Inspira Lab. E-mail: igaviriamesa@yahoo.es. Orcid 0000-0003-38993012. Calle 56 No 47-23 Medellín.

** Colombiana. Coautora. Abogada de la Universidad de Medellín. Magíster en Derecho Procesal de la Universidad de Medellín. Especialista en Derecho Laboral y la Seguridad Social de la Universidad Pontificia Bolivariana. Pertenece al Grupo de Investigación Jurídicas y Sociales de la Universidad Católica Luis Amigó. Este artículo es un avance de la investigación denominada: "responsabilidad social empresarial en el marco del postacuerdo de paz" desarrollado durante el año 2017 y auspiciado por la Universidad Católica Luis Amigó e Inspira Lab. E-mail: monigranda@hotmail.com Orcid 0000-0002-8986-9217. Calle 48 sur 39-57 Urbanización Guayacán de la Plaza, Envigado.

**** Colombiano. Coautor. Publicista de la Universidad Pontificia Bolivariana. Doctor Degree in visual communication de Presley University, MBA con especialidad en gestión de la calidad, seguridad y medioambiente de la Universidad Viña del Mar. Docente de Tiempo Completo de la Universidad Católica Luis Amigó (Funlam). Pertenece al grupo de investigación URBANITAS de la Funlam. Este artículo es un avance de la investigación denominada: "responsabilidad social empresarial en el marco del postacuerdo de paz" desarrollado durante el año 2017 y auspiciado por la Universidad Católica Luis Amigó e Inspira Lab. Email: juan.lopezme@ amigo.edu.co Orcid: 0000-0002-3105-8980. Transversal 51 A 67 B 90 Medellín

***** Colombiano. Coautor. Publicista de la Universidad Central. Magister en Educación de la Universidad Bolivariana de Chile. Especialista en Docencia Investigativa Universitaria y en Gestión Educativa de la Universidad Católica Luis Amigó. Director del Programa de Publicidad de la Universidad Católica Luis Amigó. Este artículo es un avance de la investigación denominada: "responsabilidad social empresarial en el marco del postacuerdo de paz" desarrollado durante el año 2017 y auspiciado por la Universidad Católica Luis Amigó e Inspira Lab. Orcid: 0000-0002-3178-6312. Correo electrónico: rafaelvargascano1 @ hotmail.es Transversal 51 A 67 B 90 Medellín
} 


\begin{abstract}
The fundamental cause of the violence in Colombia has been the inequality in the division of the land, one of the most unequal in the world. Regarding this issue, the Colombian state has had two perspectives: either they have been wrong or have been conceived in a malicious way to favor a minority, in detriment of the peasant conglomerate. Such foolishness or insanity has had a violent expression that might be stopped through public development and in the long term through the Havana Peace Accords.
\end{abstract}

Key words: inequality, land, State, violence, accords

Recibido:

Aceptado:

\title{
Introducción
}

La economía, como disciplina social, no es reductible a la cifra abstracta de los expertos en estadística, es decir, no es simple econometría, sino, ante todo, decisión política, lo que no significa prescindir de las mediciones que se expresan en números. El conocimiento de la realidad humana camina sobre dos pilares: las reflexiones teóricas y la matematización del mundo, derivada de la innata búsqueda del hombre por la seguridad que ofrece el rigor de lo mensurable. Resulta inocua toda decisión en economía sin previas consideraciones políticas, y estas requieren a su vez un fundamento verificable que se aproxime a la exactitud; lo contrario sería como los repetidos golpes de bastón del ciego en la oscuridad de un laberinto. En Colombia la guerra ha sido determinación política con rotundas consecuencias económicas, las que a su turno han inspirado plataformas de gobierno en una incesante vuelta de tuerca que dura ya más de cincuenta años, si se atiende solo al alzamiento armado surgido en los años sesenta. Las decisiones estatales para afrontar el conflicto han resultado no solo fallidas, sino propiciadoras de su recrudecimiento, porque se han circunscrito a combatir al "enemigo interno" con la lógica maniquea de quien, desde la "razón de Estado", se arroga la bondad de sus acciones para eliminar el "mal" que amenaza la democracia. La prueba de este aserto es el conjunto de acuerdos de la Habana, demostrativos de que, si bien las FARC se sentaron debilitadas a la mesa, no estaban vencidas, por lo menos en su capacidad para comprometer ingentes proporciones del presupuesto nacional en su combate y en el pago de los estragos de la guerra. El informe presentado por el Departamento de Planeación Nacional ${ }^{1}$, con ocasión de los quince años del Plan Colombia mueve al asombro, indica: "Mientras Estados Unidos apoyaba al país con 9.600 millones de dólares en los últimos quince años, el Estado colombiano en igual período de tiempo destinó 131.000 millones de dólares para el fortalecimiento del sector defensa". La deuda externa de Colombia llega para el mes de junio de 2017 a 127mil millones de dólares ${ }^{2}$, lo que da cuenta del caudal gastado en un solo objetivo, esto es un $8 \%$ más del monto de la deuda, en el conflicto armado interno. Ciento treinta y un mil millones

\footnotetext{
${ }^{1}$ Departamento Nacional de Planeación, El plan que le cambió la cara al país: DNP, Bogotá, Departamento Nacional de Planeación, 2016.

2 Dinero, “Así va la deuda del Gobierno en 2017”, Dinero, 2017.
} 
de dólares que, invertidos en proyectos de desarrollo en las zonas afectadas por la violencia, habrían evitado la incorporación cotidiana, durante medio siglo, de hombres y mujeres a los grupos guerrilleros o a las bandas paramilitares. El Plan Colombia, estrategia para eliminar la producción de coca y de paso a sus sembradores y negociantes, no surtió los efectos pretendidos; al contrario, disparó los precios de los estupefacientes y encareció el cultivo de su materia prima, a más de los muertos y el desarraigo que asciende a cifras apocalípticas. No cerró la enorme brecha social que, como herida sangrante, ubica a Colombia en un lugar de inequidad mundial vergonzoso. La genuina y efectiva desactivación de la guerra en una sociedad empobrecida no es la estrategia bélica con efectivos militares y asesorías foráneas onerosas, sino la acción positiva del Estado a lo largo del territorio nacional, en cumplimiento de su función social, que no represiva, como lo ordena la carta Magna.

En el caso concreto de la tierra, su tenencia y desarrollo, Colombia es el típico contraejemplo de lo que se debe y puede hacer para impedir los conflictos por su posesión. La evidencia es incontestable: según $\mathrm{ACNUR}^{3}$, el número de desplazados en el 2017 alcanzó siete millones cuatrocientas mil personas, en su mayoría, provenientes del campo. El minifundista ha sido la víctima propiciatoria de quienes quieren la tierra por ambición económica o por estrategia militar como territorio ocupado. Ni la modernizante reforma de López Pumarejo en 1936 ni los adocenados planes de intervención estatal en su reparto, han producido efectos benéficos. El despojo de ayer, sigue en el presente, incluso con métodos similares: sangre y engaño. No es un secreto que Colombia por naturaleza -más que por vocación- tuvo su enfoque de desarrollo en el sector agrario, hoy reemplazado por la economía extractiva o por cultivos que en nada favorecen el sector campesino, como la palma de aceite sembrada en vastas zonas de desplazados.

En este orden de ideas, este trabajo está compuesto de tres partes. La primera aborda las causas estructurales de la desigualdad rural en Colombia, como epifenómeno del desequilibrio macroeconómico en las demás esferas, que han afectado la estabilidad nacional. La segunda se enfoca en el conflicto interno armado y sus efectos en punto a la apropiación de la tierra, como causa inmediata y no superada de la guerra, pese a las normas que en este aspecto dispuso el Constituyente de 1991 y que se plasmaron en la Carta; en último lugar, se analizan los puntos centrales de los acuerdos de la Habana entre el gobierno de Juan Manuel Santos y las FARC, en lo atinente a un nuevo modelo agrario y, en consecuencia, a una diferente lógica de la acción del Estado en el campo, sin el fantasma de la guerra.

\section{LA TIERRA Y SUS DUEÑOS EN COLOMBIA.}

Oxfam Internacional, en su informe de 2016 sobre la tierra en el planeta sostiene que el $1 \%$ de las fincas acapara más de la mitad de la superficie productiva. Es decir, este 1\% concentra más tierra que el $99 \%$ restante ${ }^{4}$. Esta situación no ofrece un camino para el desarrollo sostenible ni para los países ni para las poblaciones.

\footnotetext{
${ }^{3}$ ACNUR, 2016: Desplazamiento forzado alcanza nuevo récord, 2017.

${ }^{4}$ Oxfam Internacional, Desterrado: tierra, poder y desigualdad en América Latina, 2016, 5.
} 
Además, según el Instituto Geológico Agustín Codazzi (IGAC) el territorio colombiano cuenta con 114 millones de hectáreas aproximadamente, 54\% en manos de propietarios privados. En el índice Gini Colombia muestra un 89,7 de desigualdad, siendo cien (100) la plena desigualdad ${ }^{5}$. Con esta cifra es imposible el desarrollo y muy seguro el conflicto. Esto que hoy se ve con asombro -aunque les termina importando poco a la sociedad y al Estadoera una situación natural en los albores del siglo XX en Colombia. Las "élites regionales", en palabras de Alejandro Reyes ${ }^{6}$ se hicieron a la tierra como compensación en el siglo XIX por sus servicios a la guerra de independencia, en exclusión de los campesinos que cumplieron funciones de siervos hasta el gobierno de López Pumarejo, quien con una novedosa pero no menos tímida reforma agraria y en oposición al establishment, promulgó la ley 200 por cuya virtud serían propietarios los poseedores que demostraran 20 años en tal condición y en algunos casos, solo se exigían cinco años para la prescripción adquisitiva. Al respecto escribe Fernán González: "Esto entrañaba la legitimación práctica de las usurpaciones realizadas en el siglo precedente, lo que, se suponía, habría de frenar el movimiento de los colonos (...) La ley 200, con su actitud frente a los propietarios y campesinos, es una muestra de un estilo reformista a medias" $"$.

Fue una reforma de claro tinte burgués, ya que no se trataba de darle la tierra a quien no la tenía, sino de ofrecerle la oportunidad al propietario de "sanear sus títulos y de poner el suelo en explotación, so pena de revertir al Estado" ". Esta ley tuvo dos objetivos concretos: modernizar y aumentar la producción agraria en el país, y además ponerle fín a las modalidades de aparcería feudal por las cuales eran vinculados los jornaleros del campo. En este último caso, los aparceros y arrendatarios se convirtieron en asalariados ${ }^{9}$. No fue una "revolución agraria" como la que se intentó en México en 1910 ni un proceso de colectivización al estilo soviético, sino una modificación apenas modesta que le imprimió una función social a la propiedad de la tierra, en favor de una minoría. Pese a ello, los latifundistas se organizaron en la APEN (Asociación de Propietarios y Empresarios Nacionales) a efecto de defender lo que consideraban sagrado y por ello inamovible: los privilegios en la tenencia y destinación de la tierra ${ }^{10}$. Como en el presente, con el gremio ganadero y su oposición a la reforma agraria acordada en la Habana, los de aquellos años afilaron los machetes para obstaculizar la aplicación de las tímidas normas de la ley 200. La violencia en los campos en la década del cuarenta fue, más que una querella por colores políticos, el resultado de un incipiente intento de modernización agraria. La APEN se constituyó para confrontar por la vía armada lo que la ley había instituido, bajo la inspiración de López Pumarejo.

El asesinato de Jorge Eliécer Gaitán en 1948 abortó un proyecto reivindicatorio de

${ }^{5}$ El Tiempo, El 64\% de hogares rurales no cuentan con acceso a la tierra, El Tiempo, 26 de noviembre de 2016.

${ }^{6}$ Alejandro Reyes, Guerreros y campesino. El despojo de la tierra en Colombia, Bogotá, Norma, 2009, 25.

${ }^{7}$ Fernán González, Poder y violencia en Colombia, Bogotá, ODECOFI, 2014, 268-269.

${ }^{8}$ Gerardo Molina, Las ideas liberales en Colombia, Bogotá, Tercer Mundo editores, 1990, 30.

${ }^{9}$ González, op. cit., 267.

${ }^{10}$ Gabriel Poveda, Historia de la economía colombiana, Medellín, Universidad Pontifica Bolivariana, 2005. 
carácter político y social ante el que las castas vieron en vilo sus privilegios centenarios. La oposición entre pueblo y oligarquía fue el estribillo de guerra repetido por Gaitán que caló en la masa y la dispuso para el combate al oír a un figura mesiánica y populista, portador de un verbo incendiario, abstruso pero efectivo. Expresiones como "El país político" contra "el país nacional" demostrativas de la relación dialéctica de clase marxista expuesta por un abogado salido de la entraña popular, o la "Plutocracia", término que el líder liberal acuñó para describir la naturaleza concupiscente de los gobernantes en Colombia, caracterizaron sus discursos. Gaitán logró, según González "Una adhesión popular sin antecedentes en la historia colombiana" 11 superando cualquier otro fervor electoral. En el punto específico sobre la tierra, Gaitán consideraba la necesidad de intervención estatal en su reparto a efecto de compensar los desequilibrios estructurales que presenta; de igual manera, propugnaba la adjudicación a quien la hubiere cultivado en desarrollo de su función social, sin atender a títulos preexistentes; defendió la propiedad comunal de los indígenas en concordancia con su cosmovisión de la tierra y propuso la planificación estatal en la producción agrícola, de acuerdo con las necesidades no solo nacionales, sino de cada región, así como proponía la obligatoria producción de alimentos de primera necesidad ${ }^{12}$. No estaban dispuestas las élites para el cambio, pero sí buena parte del pueblo, de allí la reacción ante el magnicidio. Del "Bogotazo" quedó una amarga lección, que se repetiría en años posteriores: las elecciones en Colombia no son más que la certificación cada tanto del poder en las mismas manos.

En 1950, sin opositor electoral, Laureano Gómez obtuvo la presidencia de la república con un plan de Estado tan paradójico en su título como inocuo en sus resultados: "La revolución del orden". Inspirado en el generalísimo Franco y en Oliveira Salazar, dictador de Portugal, Gómez soñó con un gobierno en el que la mixtura entre Cristo y Bolívar reimplantara la paz que los masones y el comunismo internacional habían arruinado ${ }^{13}$. Su fugaz período en la primera magistratura, dadas las convulsiones políticas y sociales de la época, le impidieron poner en ejecución sus proyectos. Ofició más como jefe de un ejército en trinchera que como presidente de un país. En educación apenas pudo terminar los edificios de la universidad Nacional, además de que impulsó la educación normalista. En la salud pública, promovió campañas de vacunación contra la malaria y la fiebre amarilla. En obra públicas, construyó el oleoducto de Puerto-Salgar y el de Puerto Berrío ${ }^{14}$. De política agraria lo único destacable fue la consigna de persecución sin tregua al enemigo liberal agazapado en los campos. A finales de octubre de 1951 abandonó el poder, huyó a España y su lugar lo ocupó el designado Roberto Urdaneta Arbeláez.

La marginalidad rural de la primera mitad del siglo XX en Colombia fue objeto de investigación por expertos foráneos, siendo las más destacadas la misión Currie y la Lebret. Los datos que arrojaron ofrecen la prueba inconcusa de que la pobreza sí obró como detonante de violencia, es decir, que el crimen de Gaitán fue causa política inmediata, pero

\footnotetext{
${ }^{11}$ González, op. cit., 279.

${ }^{12}$ Molina, op. cit.

${ }^{13}$ Marco Palacios, Entre la legitimidad y la violencia, Bogotá, Norma, 1995.

${ }^{14}$ Poveda, op. cit.
} 
las aguas turbias de la guerra se venían represando a lo largo de los años, en virtud de la secular inequidad en la distribución de la riqueza. Veamos algunas cifras. El informe Currie $^{15}$ de 1950 demostró que la renta promedio en 1947 de los campesinos era de \$ 602,00 (seiscientos dos pesos), con la consecuente pésima calidad de vida expresada en malnutrición y mortalidad infantil por encima de la media en el mundo subdesarrollado. Además, de los ingresos totales, el $90 \%$ de los trabajadores agrarios "recibió rentas inferiores al promedio de $\$ 1.073,00$ (mil setenta y tres pesos), mientras que un $2.5 \%$ de los rentados percibieron rentas diez veces mayores que el promedio general" ${ }^{16}$. Por su parte, la misión Lebret descubrió las condiciones casi primitivas de los habitantes del campo ${ }^{17}$. En ambas investigaciones se concluye que la vida del campesinado se reducía a la subsistencia, mediante la venta de lo que la parcela les daba. La tierra labrada hasta la extenuación, termina erosionándola, con la lógica consecuencia de su improductividad ${ }^{18}$. El imposible acceso a créditos por parte del Estado, convertían la vida de los minifundistas en un círculo vicioso de pobreza, porque sin recursos no hay capacidad de inversión y menos aún, de tecnificación, y ante esto, no hay esperanza de desarrollo agrario masivo, solo miseria que se reproduce y se extiende.

Si bien parece cierto que la Violencia en Colombia arrojó más de trescientos mil muertos, víctimas del enfrentamiento bipartidista, se ignora la precisa cantidad de desplazados que, en medio del horror, abandonaron las parcelas. La confrontación liberalconservadora fue el hecho conocido y explicativo de los asesinatos y del desarraigo, pero sirvió para expropiar a los campesinos de sus terruños, en una especie de contra reforma agraria de facto que agudizó la desigualdad en la tenencia de la tierra a partir de aquel fenómeno. En efecto, las diferencias entre indígenas, colonos y terratenientes de un lado, y por el otro, aventureros que ocuparon las tierras expósitas constituyeron las dos causas de este primer gran despojo del siglo $\mathrm{XX}^{19}$. La adscripción a alguna bandería por parte de los labriegos -o la sola sospecha- era razón suficiente para permanecer en su suelo o ser expulsado, y sumarse a los millones de nómadas forzados que inundaron las ciudades ${ }^{20}$. El éxodo producido por el miedo generó una recomposición de la propiedad rural en el país, con cantidades ingentes de despojados y nuevos dueños -pocos- de la tierra. Aquellos llegaron a las urbes como fantasmas, a poblar las laderas de las que hicieron un hábitat que con los años se convirtió en espacio de vida, tan pobre y excluido como el de los campos. Estos conformaron una nueva élite, cuyos herederos son los que hoy defienden como centuriones lo ganado con la sangre de la Violencia.

El golpe palaciego de Gustavo Rojas Pinilla el 13 de junio de 1953 fue apoyado por una parte de la oligarquía colombiana, con el llamado "Ospinismo" a la cabeza ${ }^{21}$. Fue incruenta

\footnotetext{
${ }^{15}$ Molina, op. cit.

${ }^{16}$ Ibid., 254.

17 Ibid.

18 Idem.

19 Ana María Ibáñez, El desplazamiento forzoso en Colombia. Un camino sin retorno hacia la pobreza, Bogotá, Universidad de los Andes, 2008, 23.

${ }^{20}$ Ibáñez, op. cit.

${ }^{21}$ Palacios, op. cit.
} 
la acción, porque el desgaste de Laureano Gómez, presidente fugitivo, generó un vacío de poder y un incremento en los índices de violencia que ponían en riesgo la preservación del propio establishment. Rojas, un militar sin heroísmos, tomó las riendas del ejecutivo para congelar el orden burgués con medidas apaciguadoras como la amnistía y el indulto en favor de guerrilleros y presos políticos. Su propósito al tomar el poder lo lanzó en pocas palabras: "No más sangre, no más depredación; paz, justicia y libertad para todos"22. Los resultados se vieron: "la cifra de muertes por la violencia cayó de 22.000 en 1952-53 a 1.900 en 1954-55"23. Convocó la Asamblea Nacional Constituyente en 1954 con el propósito de consolidar su poder por vía "democrática", conformada por civiles y representantes del sector castrense. Con su respaldo emprendió reformas políticas que superaron las estratégicas expectativas de sus mentores. Si bien pacificó una parte del país, puso en marcha medidas calificadas como populistas, como el voto femenino y el desarrollo de obras públicas, además de la inauguración de la televisión. Pero de igual manera cerró periódicos y "proscribió el partido comunista y reemplazó las Asambleas departamentales y los Consejos municipales por cuerpos administrativos" ${ }^{24}$. En el agro, impulsó la producción cafetera logrando una bonanza inédita en el país, cuyos réditos absorbió el cuantioso gasto público. Pero de la entrega de armas no se derivó la justicia que los campesinos pretendían. Vinieron las retaliaciones contra los indultados y el "golpe de opinión" que lo sacó del poder en 1957.

La Comisión Económica para América Latina y el Caribe-CEPAL- ${ }^{25}$, en un informe presentado en 1957 mostró la distribución de la propiedad rural para 1955 en las siguientes magnitudes:

Tabla 1 Distribución del tamaño de propiedades rurales 1955

\begin{tabular}{lllll}
\hline $\begin{array}{c}\text { Tamaños de } \\
\text { Hectáreas }\end{array}$ & $\begin{array}{c}\text { Número de } \\
\text { predios }\end{array}$ & Porcentaje & $\begin{array}{c}\text { Superficie } \\
\text { ocupada Miles } \\
\text { de hectáreas }\end{array}$ & Porcentaje \\
\hline Menos de 5 & 459.380 & 55.97 & 950.9 & 4.18 \\
\hline $\begin{array}{l}\text { Más de 5 } \\
\text { menos de 20 }\end{array}$ & 230.550 & 28.09 & $2.434,4$ & 10,73 \\
\hline $\begin{array}{l}\text { Más de 20 } \\
\text { menos de 100 }\end{array}$ & 101.384 & 12,35 & $4.746,1$ & 20,92 \\
\hline $\begin{array}{l}\text { Más de 100 y } \\
\text { menos de 500 }\end{array}$ & 25.072 & 3,05 & $7.521,6$ & 33,15 \\
\hline Más de 500 & 4.456 & 0,54 & $7.035,5$ & 31,02 \\
\hline
\end{tabular}

Fuente: Gabriel Poveda, Historia de la economía colombiana, 2005, 467.

Nótese la desigualdad en el tamaño de la tierra distribuida por hectáreas. El $55.97 \%$ de

${ }^{22}$ Alfredo Molano, A lomo de mula. Viajes al corazón de las FARC, Bogotá, Aguilar, 2016, 26.

${ }^{23}$ Palacios, op. Cit. 212.

${ }^{24}$ Ibid. 213-214.

${ }^{25}$ Poveda, op. cit., 467 
los predios son minifundios inferiores a cinco hectáreas, en tanto el extremo contrario, superficies de más de quinientas hectáreas solo conforma el $0.54 \%$ del conjunto de propiedades estudiadas $^{26}$. Ni la estrategia civilizatoria de López Pumarejo con su ley 200 en el intento de poner a tono el país con el capitalismo internacional ni el asesinato de un caudillo ni los largos años de conflicto bipartidista ni el golpe militar ni el proceso de pacificación, lograron en plena mitad del siglo $\mathrm{XX}$, un progreso por lo menos tímido en el medieval sistema de distribución de la tierra en Colombia.

El modelo democrático liberal tiene como requisito ontológico un sistema electoral garantista de reglas ciertas para resultados inciertos. Es decir, condiciones de participación realmente amplias, sin discriminaciones violatorias de la dignidad humana por razones de clase social, raciales, económicas o ideológicas. Esto en teoría, porque el experimento de repartición del poder en Colombia concebido por Laureano Gómez, como vocero del partido conservador, y Alberto Lleras Camargo de la divisa liberal, para enervar la violencia política mediante los pactos de Benidorm y Sitges, convirtió la utopía pluralista que toda sociedad busca, en dictadura comicial. Ambos concibieron el Frente Nacional (FN) a la manera de un bálsamo en las heridas de la guerra y, a la vez, como fórmula salvífica de las instituciones. El experimento es simple de explicar, pero difícil de aceptar, sobre todo después de un balance histórico crítico. Se trataba de alternar en el dominio del Estado -no solo de la presidencia de la república como muchos creen- cada cuatro años durante cuatro períodos que empezaron en 1958 a ambas conformaciones políticas. El poder quedaría en manos de los partidos tradicionales que se apoyarían mutuamente en oposición a cualquier otra aspiración distinta. En términos sencillos, la democracia no podía ser distinta a la liberal-conservadora independiente de que las heterodoxias políticas reclamaran espacio en el espectro electoral, como ocurrió con el Partido Comunista o con el Movimiento Revolucionario Liberal (MRL). Si bien se redujo la violencia rural promovida por las élites, el conflicto social tomó no solo dimensiones distintas, sino más dramáticas. Como lo afirma Francisco Gutiérrez "Si el Frente Nacional (FN) fue un experimento institucional que obtuvo numerosos éxitos, hay más de un motivo para la perplejidad en cuanto a la relación entre partidos y régimen" 27 . La exclusión política de amplios sectores, el olvido de lo social, la corrupción partidista y el incremento de la pobreza, empedraron el camino de las nuevas violencias. En los años sesenta surgen como por ensalmo en Colombia expresiones armadas de izquierda, en el cuadro internacional de la guerra fría. El grupo con un origen agrario genuino fue el que lideró Manuel Marulanda Vélez, las Fuerzas Armadas Revolucionarias de Colombia en 1964. Las antiguas "chusmas" liberales se asentaron en Marquetalia, Rio chiquito, El Pato, Guayabero y Sumapaz con el objetivo de crear zonas agrícolas autosuficientes, ante el olvido del Estado. Álvaro Gómez Hurtado calificó esas zonas ocupadas por campesinos sin tierra como "Repúblicas independientes", por lo que Guillermo León Valencia, a la sazón presidente de Colombia -el segundo del FN-, ordenó su bombardeo. El tumor benigno hizo metástasis: los labriegos mudaron en feroces guerrilleros armados, no de machetes y azadones viejos, sino de fusiles, granadas y, sobre todo, de ideología combativa. Luego serían el ELN, el EPL y en los setenta, el M-19, entre

\footnotetext{
${ }^{26}$ Idem.

${ }^{27}$ Francisco Gutiérrez, Lo que el viento se llevó, Bogotá, Norma, 2007, 75.
} 
otros. De 1958 a 1974, año de culminación del Frente Nacional, no hubo más democracia ni más tierra ni menos violencia.

\section{La mutación del conflicto armado en Colombia}

El enfrentamiento partidista de los años cincuenta se transformó en insurrección armada contra el Estado, a partir del arreglo burocrático de los dos líderes de las banderías tradicionales. La política de tierras del Frente Nacional en su conjunto, fue un rotundo fracaso. El siguiente es un compendio de las diversas reformas agrarias durante este período, que por inoperantes desataron mayores y más complejos conflictos. La ley 135 de 1961 que creó el INCORA (Instituto Colombiano para la Reforma Agraria) "con tres lineamientos estratégicos: dotar de tierras a los campesinos, adecuar tierras para incorporarlas a la producción, y prestar servicios sociales básicos y otros apoyos complementarios" 28 , no superó la retórica legal. En efecto, la gestión de Alberto Lleras Camargo como primer mandatario del Frente Nacional tuvo una dimensión económica en el escenario complejo de una América Latina inmersa en la guerra fría, alinderada con los Estados Unidos. Para impedir la propagación "infecciosa" de la revolución cubana, Jhon F. Kennedy promovió la Alianza para el Progreso, un conjunto de medidas para reducir la pobreza sin alterar el sistema de privilegios de las burguesías del continente, y en consecuencia someter al aislamiento la nación caribeña. Una cifra cercana a los diez mil millones de dólares distribuyó Estados Unidos en el continente por diversas vías. Colombia se benefició no sólo de créditos para construcción de complejos habitacionales, acueductos, alcantarillados, electrificación, sino además de donaciones de alimentos con el estratégico cometido de evitar insurrecciones armadas. De igual manera, Kennedy recomendó la ejecución de reformas en temas sensibles que exigieran urgente atención. La tenencia de la tierra, como se advirtió en líneas anteriores, ha sido una herida abierta en Colombia por la cual se han suscitado conflictos de toda índole, que la ley 135 pretendió eliminar. Los objetivos de esta reforma fueron:

Reformar la estructura social agraria y prevenir la inequitativa concentración de la tierra; fomentar la adecuada explotación económica de tierras incultas; acrecentar el volumen global de la producción agrícola y ganadera en armonía con el desarrollo de los otros sectores económicos; crear condiciones bajo las cuales los pequeños arrendatarios y aparceros gocen de mejores garantías; elevar el nivel de vida de la población campesina...con asistencia técnica, el crédito agrícola, la vivienda, la organización de los mercados, la salud y la seguridad social; asegurar la conservación, defensa, mejoramiento y adecuada utilización de los recursos naturales ${ }^{29}$.

Aunque debe aclararse que con esta reforma se modificó la figura de la expropiación contenida en la ley 200 de 1936 -enervada a su vez por la ley 100 de 1944- y en su lugar se

\footnotetext{
${ }_{28}$ Álvaro Albán, "Reforma y Contrarreforma Agraria en Colombia”, Revista de economía institucional, 24:13, Bogotá, 2011, 347.

${ }^{29}$ Poveda, op. cit., 471.
} 
instauró la venta de tierras. Para tal efecto, el INCORA compraría las tierras y las adjudicaría en función de las necesidades de cada zona.

Carlos Lleras Restrepo (1966-1970) complementó la ley 135 con la $1^{\text {a }}$ de 1968 que disponía mayor inversión en el campo, en aras de desarrollar actividades agrícolas estancadas, pese a la reforma anterior. Creó la Asociación Nacional de Usuarios Campesinos (ANUC) como cuerpo organizado para enfrentar a la oligarquía rural, y llevó a cabo inversiones cuantiosas en el desarrollo agrícola. No obstante, la violencia extendida en vastas zonas del país y la férrea oposición de los latifundistas a estas medidas, hicieron nugatorio el espíritu de las reformas. El presidente Misael Pastrana Borrero (1970-1974) promovió la contrarreforma agraria con el auspicio de terratenientes interesados en congelar todo conato de progreso en la distribución de la tierra. En 1972 se reunieron las élites rurales en el municipio de Chicoral (Tolima) para fraguar las medidas que contrarrestarían el "despojo" del que fueron "víctimas" por arte de leyes que ordenaban mayor inversión y desarrollo agrario. El famoso "Pacto de Chicoral", expresión de lo que García denominó un "latifundio arcaico"30, mediante la ley $4^{\mathrm{a}}$ de 1972 logró disolver la incipiente voluntad del Estado de transformar los vínculos Señor-siervo del agro en Colombia, en relaciones capitalistas, con un mercado rural moderno, tecnificación y sistemas de crédito acordes con la capacidad de pago de los minifundistas, además de ampliar la base de titulación campesina a tierras con vocación productiva de alimentos y no de simple explotación ganadera. Fue así como la ley 4 a impuso la "Calificación de tierras", a efecto de determinar aquellas debidamente explotadas; también, prescribió la "Forma de pagar" las tierras sobre las que se demostrara una adecuada explotación e impuso la figura de la "Renta presuntiva" fijando un mínimo de renta del $10 \%$ de su valor catastral ${ }^{31}$.

El balance del Frente Nacional en punto a lo que algún teórico llamó "la cuestión agraria" es deleznable: entre 1960 y 1988 el coeficiente Gini pasó del 0,86 al 0,84 ${ }^{32}$. Es decir, los 16 años de obstrucción democrática (1958-1974) sirvieron para concentrar el poder político y el poder de la tierra en pocas manos. El FN no impuso la equidad en la distribución de la tierra, solo matizó el despojo con incisos y discursos: "Cincuenta años de intentos relativamente ineficaces (y costosos) para implementar la reforma agraria sugieren que la mayoría de los cambios realizados a este respecto fueron la respuesta a una presión ad hoc, sin una evaluación sistemática de las lecciones aprendidas con la experiencia, tanto en Colombia como a escala internacional" 33 .

Presión ad hoc, o por la violencia popular o por la exigencia de los poderes económicos, convierte lo que debería ser una política de Estado en maquillaje jurídico circunstancial.

\footnotetext{
30 Antonio García, La estructura del atraso en América Latina. Hacia una teoría latinoamericana del desarrollo, Bogotá, Convenio Andrés Bello, 2006, 228.

${ }^{31}$ Gilberto Arango, Estructura económica colombiana, Bogotá, Mc Graw Hill, 2005, 66.

32 Darío Fajardo, Cuadernos tierra y justicia. Tierra, poder político y reformas agraria y rural, Bogotá, Antropos, 2002, 5.

${ }^{33}$ Isabel Lavadenz y Klaus Deininger, "Políticas de tierras", Marcelo Giugale, Olivier Lafourcade y Coniie Luff (Comps), Colombia fundamentos económicos de la paz, Bogotá, Banco Mundial y Alfaomega, 2003, 512.
} 
Escribe Palacios: "Para 1971 apenas había expropiado algo así como el 1\% de las superficies legalmente afectables (...) La historia política de la reforma está ligada a la expansión del patronazgo y del clientelismo"34. Si bien la ley 135 logró un cierto avance en la adjudicación de tierras, la cifra de adquisición de predios por vía expropiativa es risible: "Entre 1962 y 1970 no alcanzó a afectar ni el 1\% de la superficie agropecuaria del país"35.

En el gobierno del "Mandato claro" (Alfonso López Michelsen 1974-1978) se expidió la Ley $6^{\text {a }}$ del 10 enero de 1975 que reguló la aparcería, contrato no inferior a tres años, por el cual propietario y aparcero explotan un fundo con mutua ganancia de los frutos. No dispuso tiempo de prescripción por inactividad del propietario en cuanto al contrato ni posibilidad de que el campesino que oficiaba como aparcero, adquiriera la titularidad de la tierra. Es un nexo legal que congela la relación entre el dueño de la tierra y el trabajador en una figura parecida a la estamentaria de naturaleza feudal. En efecto, el artículo 6 de esta ley establecía:

Los contratantes podrán determinar que el propietario entregue al aparcero, adicionalmente a la parcela dada en aparcería, una porción de tierra para su uso y goce exclusivo ubicada en el lugar en que ellos convengan, de preferencia en un sitio próximo a la vivienda del aparcero, con derecho a establecer en ella cultivos de pronto rendimiento, básicos para su alimentación.

Las huellas de un pasado en el que las diferencias sociales estaban concentradas en la posesión de la tierra, están claras en esta norma. Se buscó la productividad de la tierra sin afectar su titularidad, esto es, sin alterar los privilegios del sistema latifundista, causa de largas y sangrientas violencias.

Por su parte, los años ochenta trajeron nuevas dinámicas sociales, políticas y de orden público. La irrupción del narcotráfico a gran escala, el ascenso de un gobierno que como el de Belisario Betancur intentó por primera vez acercamientos con la insurrección armada, la conformación de grupos paramilitares en Puerto Boyacá -declarada Capital antisubversiva de Colombia- como epicentro de sus acciones y el crecimiento exponencial de los frentes de las FARC, entre otras, generaron impactos sensibles en la economía rural. Tomó fuerza el fenómeno del desplazamiento en vastas zonas de la geografía nacional, en espacios que no solo eran objeto de ambición de terratenientes en contubernio con organizaciones mafiosas, sino que representaron territorios estratégicos de hegemonía militar para los bandos enfrentados. Es así como aunada a la pobreza, la violencia constituirá de nuevo, como en los años cincuenta, una concausa de abandono del campo. El fracaso reiterado y doloso de las reformas agrarias a lo largo de la historia en el país tendrá como compañera la presión de grupos armados que, con el pretexto de la autodefensa, emprenderán el proyecto de contra reforma de la tierra más grande e inédito en Colombia y en América latina. La pauperización en el campo nutrió los grupos armados que reivindicaban aquel díctum

\footnotetext{
${ }^{34}$ Palacios, op. Cit. 255.

35 Javier Giraldo, Conflicto social y rebelión armada en Colombia. Ensayos críticos, Bogotá, Gentes del Común, 2015, 219.
} 
bíblico de que "la tierra es para el que la trabaja" ya no como clamor de desarraigados, sino a manera de exigencia violenta, lo que a su vez se erigió en pretexto de los terratenientes para organizar ejércitos mercenarios de "protección", ante la indiferencia del Estado. Lo paradójico de este hecho es que si fue cierto que los propietarios de la tierra se armaron porque estaban huérfanos de Estado, también lo fue que expandieron su dominio territorial gracias a la inacción e incluso a la complicidad de agentes estatales. El punto central en todo caso radica en que lo que en principio se alegó como legítima defensa de la propiedad rural, mudó en guerra a muerte contra los minifundistas sin atender a filiaciones ideológicas. En el centro del aparente conflicto de ideas de izquierda o de derecha, estaba la posesión de la tierra; el exterminio del "enemigo comunista" fue la trampa de apoderamiento de más de ocho millones de hectáreas en veinte años por parte de paramilitares y terratenientes. No hubo defensa de la tierra que tenían, porque los campesinos no representaban ningún peligro, sino expansión territorial y desplazamiento forzado. Sin establecer la fecha precisa del nacimiento de la nueva generación paramilitar heredera de los Pájaros de la Violencia-. María Teresa Ronderos afirma que fue posiblemente en 1979 la fecha de aparición del monstruo: "Debió ser en 1979 cuando brotó la primera semilla de lo que iba a ser el principal grupo paramilitar del país durante casi una década. Es el año en que las FARC crearon su feroz Frente XI y el mismo en que el Ejército, bajo las extremas normas del Estatuto de Seguridad de Turbay, montó el Batallón Bárbula en Puerto Boyacá"36.

No obstante, hay prueba palmaria de que las bandas contrainsurgentes fueron procreadas por el Decreto 3398 de 1965 bajo la administración de Guillermo León Valencia en obsecuente cumplimiento de la orden impartida por Estados Unidos en el marco de la guerra fría. Fue así como en 1962 la Misión Yarborough de visita en Colombia, conformada por oficiales de la Escuela de Guerra Especial de Fort Bragg, recomendó la conformación de grupos cívico-militares de manera clandestina, en caso de que fuera necesario para preservar la seguridad nacional ${ }^{37}$. Aquellas aguas trajeron los lodos de hoy. En realidad, las llamadas "autodefensas" fueron el "remedio" anticipado a la reacción por una enfermedad llamada pobreza que había generado un cambio de sistema político en la isla más grande del Caribe y más cercana a Estados Unidos: Cuba.

La estrategia paramilitar patrocinada por un importante sector del latifundio del país contó con oposición popular expresada en movilizaciones en protesta, no solo por el despojo criminal del que eran víctimas los campesinos, sino por la desidia de las instituciones. En un período de 11 años (1980-1991) se registraron en Colombia 2.634 marchas rurales en 479 municipios ${ }^{38}$. Esto exacerbó aún más el odio de los terratenientes que veían en estas reclamaciones la influencia guerrillera, lo que desembocó en las masacres que perpetraron las "autodefensas" en una orgía de sangre cuyos objetivos se lograron a cabalidad: silencio, muerte y huida. En números la retórica se entiende más fácil. Entre 1985 y 2013 hubo alrededor de 166 mil civiles víctimas mortales en Colombia por el

\footnotetext{
${ }^{36}$ María Teresa Ronderos, Guerras recicladas, Bogotá, Aguilar, 2014, 33.

${ }^{37}$ Giraldo, op. Cit.

${ }^{38}$ Reyes, op. cit.
} 
conflicto armado y 25 mil desaparecidos. La cifra de matanzas produce espanto: 1.982 masacres entre 1980 y 2012, de las cuales los grupos paramilitares perpetraron 1.166, es decir el 58,9\%, las guerrillas ejecutaron 343 y la Fuerza Pública,158, lo que equivale al $17,3 \%$ y $7,9 \%$ respectivamente $^{39}$.

Con la ley 35 de 1982 se creó el Plan Nacional de Rehabilitación (PNR) con el objetivo de llevar la presencia del Estado a zonas secularmente abandonadas, asumidas como espacios de guerra y de cultivos ilícitos. Se quiso incentivar la producción pecuaria, lechera y de porcicultura, asignando ingresos permanentes, sin desmedro de la iniciativa de los propietarios para generar producción en plazos cortos. Una ley concebida para el conflicto agrario aplicada en zonas de guerra.

En el escenario de guerra y desplazamiento rural que se viene describiendo, el presidente Virgilio Barco (1986-1990) promulgó la ley 30 de 1988 con el objetivo de ampliar la adjudicación de predios con el INCORA, no sólo como instancia idónea en el proceso de compra de tierras, sino con la tarea de dotarlas de condiciones aptas para la producción. Esta ley buscó insertar al campesinado en la dinámica económica global que ya venía imponiéndose en América Latina y alejarlo de toda influencia subversiva con el argumento de la exclusión. Para ello:

Eliminó la calificación de predios (bien o mal explotados), como criterio para determinar cuáles pueden ser expropiados y la reemplazó por el criterio de necesidad para el desarrollo de los programas agrarios (...) Se elimina el concepto simplista de expropiar grandes propiedades sólo por su tamaño, sin tener en cuenta la calidad y el uso de las tierras ${ }^{40}$.

De igual manera esta ley creó la "unidad agrícola familiar" (UAF), concebida como pequeño fundo de producción no transferible comercialmente en un período de 15 años a partir de su adjudicación, sin previo permiso del INCORA. En un momento de pugna territorial entre grupos contra y para estatales y en el que los minifundistas resultaban presa fácil de compras baratas de sus tierras bajo amenazas, el gobierno nacional concibió una política de preservación de los pequeños predios, en aras de impedir desplazamientos masivos, expansión geográfica de los ejércitos ilegales y lograr un aumento de producción alimentaria, en inminente riesgo por el desamparo de los labriegos. Fue otra reforma agraria inane, como lo demostrarán los hechos posteriores.

El asesinato de Luis Carlos Galán modificó el ajedrez político en el país con el ascenso a la primera magistratura de César Gaviria Trujillo (1990-1994), ficha neoliberal en los tiempos de desmantelamiento del Estado. Con la cantinela de la ineficiencia pública y del valor inapreciable de la actividad privada, teniendo como pivote de desarrollo económico el mercado, se puso en práctica -aunque ya había germinado en el anterior gobierno- una política neoliberal sin pudor. Desregularización de las relaciones laborales, venta a precio

\footnotetext{
${ }^{39}$ Centro Nacional de Memoria Histórica, Basta ya, Colombia: memorias de guerra y dignidad. Bogotá, Centro Nacional de Memoria Histórica y Departamento para la Prosperidad Social DPS, 2013.

${ }^{40}$ Arango, op. cit., 13.
} 
de feria de los activos del Estado, con la consecuente privatización de servicios básicos, liberalización de la economía (globalización), pactos de libre comercio que exigían la apertura de fronteras para el ingreso de productos foráneos, entre ellos los alimentos, muchos de los cuales constituían la vida del agricultor en Colombia, fueron las medidas de Gaviria, cuyo lema de campaña, que no por efectista, resultó menos fantasioso "Bienvenidos al futuro", atrajo al elector. La "competencia" en los precios de la producción agrícola nacional con la extranjera, especialmente de países desarrollados, condujo a la ruina a cientos de miles de campesinos. La aplicación sin concesiones del evangelio neoliberal arrojó cifras desalentadoras en términos de progreso rural y de acceso a la tierra en Colombia. Se estima en una disminución de 850.000 hectáreas cultivadas, incremento inédito de importaciones, reducción de exportaciones, un PIB agrícola en baja, aunadas a la poca rentabilidad que en la década del noventa registró un aumento del $2 \%$, distante del 4,2\% del período 1986-1989. Resulta preocupante el decrecimiento de la superficie cosechada entre 1990 y 1998 de 3.833.115 hectáreas a 3.464.455 o sea, 9,61\% en relación a la cifra de 1990. El café, producto emblemático de la economía agrícola colombiana, mostró una merma dramática en hectáreas sembradas en los años que van de 1995 y 2003 , pasando de 869.157 a $775.000^{41}$. Esto aún bajo los parámetros de la Carta de 1991 que dispuso, en las normas atinentes a la tierra, la figura de la adquisición progresiva en condiciones que el Estado debía proveer. El artículo 64 le asigna al Estado el "deber de promover el acceso progresivo a la propiedad de la tierra de los trabajadores agrarios en forma individual o asociativa". En desarrollo de este mandato se expidió la ley 160 de 1994 que creó las "zonas de reserva campesina" (artículo 80) con el propósito de eliminar la inequitativa concentración de la tierra y promover la permanencia de los pequeños productores en sus fundos mediante la proscripción de venta de los predios. Se buscaba, al decir de Fajardo, "fortalecer el poder político de las comunidades campesinas"42. En este sentido, no es posible una real democratización en la tenencia de la tierra sin un previo escenario de democracia en la esfera agraria, sin la cual los proyectos productivos que fomente el Estado terminan en fracaso ${ }^{43}$.

El siglo XXI empezó en Colombia con una derrota de la posibilidad de la paz. Los diálogos del Caguán entre el gobierno de Andrés Pastrana y las FARC culminaron con mutuas acusaciones de incumplimiento. Una nueva figura emergió en la arena política presidencial: Álvaro Uribe Vélez. Cacique de región, Uribe había desempeñado cargos de nombramiento y de elección popular: director de la Aeronáutica civil, alcalde y concejal de Medellín, senador de la república y gobernador de Antioquia. Se opuso con terquedad a los acercamientos con la insurgencia y no dio tregua en sus invectivas contra los defensores de un modelo de paz concertada. Con un discurso antiterrorista, cautivó a buena parte del electorado, habida cuenta de que el chivo expiatorio de las desgracias de Colombia era en aquel momento, la guerrilla. A la par con la virulencia oratoria del candidato de la "mano firme y el corazón grande", se desataba en el mundo una ofensiva liderada por Estados Unidos contra el "enemigo terrorista", sin definición precisa, pero efectiva a la hora de unir

\footnotetext{
${ }^{41}$ Ibid.

${ }^{42}$ Fajardo, op. cit., 12.

${ }^{43}$ Ibid.
} 
voluntades contra lo que cuadrara en ese molde criminal. El proyecto de Estado de Uribe Vélez está concebido en el "Manifiesto democrático", circunscrito a tres factores: seguridad democrática, cohesión social y confianza inversionista. Con su triunfo en las elecciones de mayo de 2002 en primera vuelta se impuso un estilo de gobierno personalista y autoritario, en el que se diseñó una política de sometimiento simple: entrega de armas, desmovilización y rebaja de penas. Así, con la ley 975 de 2005 se entregaron los miembros de las Autodefensas Unidas de Colombia (AUC), para purgar sentencias de ocho años bajo condición de justicia, verdad y reparación. No obstante, al margen de las fundadas críticas que se le puedan formular a este proceso de entrega, en buena parte funcionó; es decir, varios miles de paramilitares junto a algunos de sus cabecillas depusieron las armas y confesaron. El punto central en cuanto a la tierra y el despojo que causaron los paramilitares estriba en que ni las confesiones ni las penas atribuidas ni las verdades dichas, lograron el retorno de los millones de desplazados. Es cierto que algunos miles han vuelto a sus predios, pero el drama continúa.

Es importante analizar los dos periodos de gobierno de Uribe en lo atinente al problema agrario, toda vez que para el año 2002, según datos de ACNUR ${ }^{44}$, Colombia tenía dos millones novecientos cuarenta y cinco mil (2.945.000) desplazados internos, un alto porcentaje rural; en el 2010, fecha de salida de este mandatario, la cifra aumentó a cinco millones. Durante los ocho años de gobierno de la Seguridad democrática no hubo medidas para impedir el desarraigo ni militares ni económicas, ya que al mismo tiempo del desarme paramilitar aparecieron las BACRIM, sus legatarias. Debe advertirse además que la ley 975 logró el desarme de efectivos paraestatales, pero no la entrega de las tierras a los campesinos expulsados. Entre 1999 y 2003 las AUC consolidaron su poder en 223 municipios, incluidos los doce más importantes del país: Antioquia, Córdoba, Sucre, Bolívar, Atlántico, Magdalena, Cesar, Guajira, Santander, Norte de Santander, Arauca y Casanare $^{45}$. Para el año 2005 las parcelas arrebatadas a los pequeños propietarios estaban en manos de testaferros o de compradores que alegaron buena fe. El statu quo agrario logrado a finales del siglo pasado y comienzos del presente con fusil y motosierra multiplicó el despojo e incrementó el abandono del campo.

Las normas que Uribe propuso como fórmulas salvadoras del agro pretendían en realidad legalizar las ocupaciones violentas de los grupos paramilitares patrocinados en buena parte por el gremio ganadero. Un ejemplo es el proyecto de Estatuto de Desarrollo Rural que admitía en una de sus disposiciones la legalidad de la posesión de un predio con cualquier prueba (artículo 121, numeral 12), lo que llevaría a la validez jurídica de ocupaciones violentas. Para colmo, este proyecto establecía un término de cinco años de prescripción adquisitiva, incluso en casos de mala fe. En virtud del repudio nacional, este proyecto no se materializó en ley, sin embargo, la obcecación de Uribe lo llevó a presentar otro plan de reconocimiento legal del crimen llamado "Saneamiento de titulación de

\footnotetext{
${ }^{44}$ ACNUR, op. cit.

${ }^{45}$ León Valencia, "Los caminos de la alianza entre los paramilitares y los políticos” Mauricio Romero (ed.), Para Política. La ruta de la expansión paramilitar y los acuerdos políticos, Bogotá, Intermedio y Corporación Nuevo Arco Iris, 2007.
} 
propiedad inmueble" con el objetivo de reducir los requisitos para obtener la titulación de predios de quienes lo hubieran registrado como falsa tradición. Mediante un trámite sumario, sin mayores exigencias, en las que no se incluía la buena fe en el acto de posesión ni atendía a las circunstancias de desplazamiento de los propietarios originales del bien, quien solicitaba la titulación podía obtenerla. En efecto, la idea se transformó en el Estatuto 1152 del 25 de junio de 2007, pero fue declarado inconstitucional con ponencia del Magistrado Nilson Pinilla (Sentencia C-175 de 2009), ante la ausencia de un requisito de carácter democrático: consultar a las comunidades indígenas las cuales tienen vocación agrícola ancestral. A esta cadena de "buenos propósitos" para el campesino se suma el programa nombrado como "Agro Ingreso seguro", enmarcado en la ley 1133 de 2007. Su cometido fue la "emprezarización del campo" 46 mediante el otorgamiento de créditos a personas o empresas que tuvieran capacidad para desarrollar proyectos de envergadura en el sector agrícola. Con ello se contribuía aún más a la aguda desigualdad rural. Por otro lado, la ley no discriminaba el origen de los títulos de quienes resultaran beneficiados con el subsidio, lo que podría haber llevado a la legalización del despojo mediante la inversión en los predios respectivos. Debe advertirse que la ley 1133 vino al mundo en medio de las discusiones del TLC con los Estados Unidos, lo que en apariencia justificaba su aplicación para proteger a los productores del campo, dado el ingreso sin aranceles de alimentos subsidiados de la potencia del norte. Bien se sabe cómo terminó Agro ingreso: en un escándalo de corrupción dadas las preferencias en los beneficios que contemplaba a círculos no solo cercanos políticamente al presidente de la república y al futuro candidato Arias, ministro de agricultura en ese momento, sino a los grandes terratenientes de las zonas en las que se llevarían a cabo macroproyectos agrarios. Recuérdese que uno de los requisitos del programa era ser empresario y, en el caso de los medianos y pequeños agricultores, esto significaba sin más, exclusión. En efecto, el aspirante al subsidio debía demostrar que contaba con un patrimonio por lo menos equivalente al $20 \%$ del total del beneficio que pedía. Asimismo, estipulaba que el proponente con mayores recursos de contrapartida del porcentaje indicado y con más hectáreas beneficiadas con el riego, obtendría más puntos.

La política agraria en el gobierno de Juan Manuel Santos no ha dado nada positivo, a excepción de los acuerdos de la Habana en este punto concreto. De allí que hay que considerar, a la par con el conjunto de cambios contenidos en los acuerdos sobre la tierra, la ley 1776 de 2016, llamada ZIDRES (Zonas de interés de desarrollo rural, económico y social). Impulsada con ahínco por Santos y que, al decir, de los expertos, resulta contraria, no solo a los intereses de los minifundistas, sino al pacto de paz con las FARC. En su contenido original esta reforma constituía una reedición del Agro Ingreso Seguro, pues determinaba la exigencia de obligar a los pequeños y medianos productores a asociarse para recibir estímulos económicos, lo que llevaría a combinar el gran capital con el trabajo. El capital, como ocurre siempre, terminaría absorbiendo la mano de obra y el pequeño fundo del campesino. Este requisito fue declarado inexequible por la Corte Constitucional. También el alto tribunal condicionó la creación de estas zonas a la previa concertación con

\footnotetext{
${ }^{46}$ Bersarión Gómez, "La tenencia de la tierra y la reforma agraria en Colombia", Verba Iuris 25, Bogotá, enero-junio 2011.
} 
los concejos municipales, además de que tienen que estar acordes con el plan de desarrollo municipal respectivo. Prohibió la Corte las ZIDRES en territorios indígenas que estén proceso de titulación como resguardos. No serán objeto de esta ley los terrenos baldíos en manos de personas naturales o jurídicas. De igual manera, el ente jurídico excluyó la exigencia prescrita en la ley que condicionaba la aprobación de proyectos productivos a la vinculación de campesinos, mujeres, jóvenes o trabajadores sin tierra.

\section{El problema de la tierra en los Acuerdos de La Habana}

Las conversaciones con las FARC culminaron con los acuerdos de la Habana, en los que la tierra ocupó un lugar central, como que allí residen en buena parte las causas del conflicto interno armado de los últimos sesenta años. En este punto, los aspectos que se pactaron se concentran en el título "Hacia un Nuevo Campo Colombiano. Reforma Rural Integral" fundado en tres ejes: 1. Dotación y formalización de tierras para el campesinado sujeto de reforma agraria; 2. Construcción de Programas de Desarrollo con Enfoque Territorial (PDETs) y 3. Construcción de la infraestructura y servicios necesarios para impulsar los motores del desarrollo regional. En cuanto al primer ítem se resaltan enfoques como el de la mujer rural, que cubre el $50 \%$ de la población campesina en Colombia, calculada en diez millones y medio de personas. El acuerdo traza políticas de acceso a la tierra para las mujeres rurales y de representación a las organizaciones que ellas conformen. Se establece también la creación del Fondo de tierras que contará con tres millones de hectáreas en sus primeros diez años, con origen en baldíos indebidamente ocupados, tierras producto de extinción de dominio, zonas de reserva forestal, tierras inexplotadas por incumplimiento de la función social y ecológica de la propiedad, tierras adquiridas o expropiadas por motivos de interés social o de utilidad pública y tierras donadas por privados. Se ofrecerán subsidios y préstamos para compra de tierra destinados a trabajadores con vocación agraria. Se llevará a cabo un proceso de formalización de siete millones de hectáreas con el propósito de regularizar y proteger los derechos de legítimos dueños y poseedores de pequeñas y medianas propiedades. La formalización rural es una tarea urgente, sin la cual, es imposible abordar la reforma en términos de reconocimiento de predios y de títulos. El acuerdo es claro al determinar "la democratización del acceso y uso adecuado de la tierra: mecanismos y garantías que permitan que el mayor número posible de hombres y mujeres habitantes del campo sin tierra o con tierra insuficiente puedan acceder a ella"47. De igual manera las partes acordaron una presencia estatal en la distribución de la tierra con subsidio integral y crédito especial para la compra de predios destinados a trabajadores y trabajadoras con vocación agraria, así como asociaciones y comunidades sin tierra o con tierra insuficiente.

Los acuerdos le dan vida a una nueva organización catastral agraria con el objetivo de aplicar el principio de progresividad tributaria. Por otro lado, el gobierno adoptará políticas de largo plazo para prevenir e impulsar soluciones a los conflictos entre la vocación de la tierra y su uso real, con base en el plan de zonificación ambiental y el principio de Bienestar y Buen Vivir. Se les da vigor a las Zonas de Reserva Campesinas con planes de

\footnotetext{
${ }^{47}$ Alto Comisionado para la Paz, Acuerdos finales de la Habana, 2016, 14.
} 
desarrollo de las zonas constituidas y de las que se constituyan. Se pondrán en ejecución además proyectos de integración regional y de acceso a los servicios sociales y a los mercados con el propósito de incidir favorablemente en los precios de los alimentos. Se implementarán planes de asistencia técnica y promoción de capacidades organizativas de las comunidades para garantizar el mantenimiento y la sostenibilidad de las obras. También habrá tecnificación en las diversas actividades agrarias como riego, drenaje, uso del agua, mitigación de riesgos por cambio climático, infraestructura eléctrica y de conectividad con el Plan Nacional de Electrificación Rural y el Plan Nacional de Conectividad Rural.

\section{Conclusión}

Las posibilidades de construir la paz en Colombia son inciertas en tanto las causas que han alimentado la guerra permanezcan inmodificadas. Una de ellas, sino la más importante, es la inequitativa repartición de la tierra en un país eminentemente agrario. Los Acuerdos de la Habana constituyen apenas una aproximación a lo que debería ser una política de Estado de largo plazo y no el producto de una coyuntura que podría ser aprovechada con fines electorales para transformar los pactos mencionados y proceder en retroceso a negar las conquistas en estos cuatro años de diálogos. La tierra en Colombia seguirá siendo un tema actual porque no sólo la violencia ha destruido el aparato productivo agrario, sino además, los tratados de libre comercio y las diferentes normas, que como la Ley Zidres, han privilegiado intereses elitistas de castas criollas o de multinacionales. En todo caso, sin una participación popular permanente que obligue a los partidos políticos y al Estado en general a tomar decisiones en favor del agro, es casi seguro que los vientos de la violencia volverán a soplar con más vigor, y posiblemente se requerirán otros cincuenta años de muertos para adquirir la conciencia de que sin una política de tierras justas es imposible la paz.

\section{Bibliografía}

Libros y artículos de revista

Alejandro Reyes, Guerreros y campesino. El despojo de la tierra en Colombia, Bogotá, Norma, 2009.

Alfredo Molano, A lomo de mula. Viajes al corazón de las FARC, Bogotá, Aguilar, 2016.

Álvaro Albán, "Reforma y Contrarreforma Agraria en Colombia" Revista de economía institucional 24:13, Bogotá, 2011, 327-356.

Ana María Ibáñez, El desplazamiento forzoso en Colombia. Un camino sin retorno hacia la pobreza, Bogotá, Universidad de los Andes, 2008.

Antonio García, La estructura del atraso en América Latina. Hacia una teoría latinoamericana del desarrollo, Bogotá, Convenio Andrés Bello, 2006. 
Bersarión Gómez, "La tenencia de la tierra y la reforma agraria en Colombia", Verba Iuris 25, Bogotá, enero-junio 2011, 63-83.

Centro Nacional de Memoria Histórica, Basta ya, Colombia: memorias de guerra y dignidad, Bogotá, Centro Nacional de Memoria Histórica y Departamento para la Prosperidad Social DPS, 2013.

Fernán González, Poder y violencia en Colombia, Bogotá, ODECOFI, 2014.

Francisco Gutiérrez, Lo que el viento se llevó. Bogotá, Norma, 2007.

Gabriel Poveda, Historia de la economía colombiana, Medellín, Universidad Pontifica Bolivariana, 2005.

Gerardo Molina, Las ideas liberales en Colombia, Bogotá, Tercer Mundo editores, 1990.

Gilberto Arango, Estructura económica colombiana, Bogotá, Mc Graw Hill, 2005.

Isabel Lavadenz y Klaus Deininger, "Políticas de tierras”, Marcelo Giugale, Olivier

Javier Giraldo, Conflicto social y rebelión armada en Colombia. Ensayos críticos, Bogotá, Gentes del Común, 2015.

Lafourcade y Coniie Luff (Comps), Colombia fundamentos económicos de la paz, Bogotá, Banco Mundial y Alfaomega, 2003.

León Valencia, "Los caminos de la alianza entre los paramilitares y los políticos", Mauricio Romero (ed.), Para Política. La ruta de la expansión paramilitar y los acuerdos políticos, Bogotá, Intermedio y Corporación Nuevo Arco Iris, 2007.

Marco Palacios, Entre la legitimidad y la violencia, Bogotá, Norma, 1995.

María Teresa Ronderos, Guerras recicladas, Bogotá, Aguilar, 2014.

Fuentes electrónicas

ACNUR, 2016: Desplazamiento forzado alcanza nuevo récord, 2017, http://www.acnur.org/recursos/estadisticas/

Alto Comisionado para la Paz, Acuerdos finales de la Habana, 2016, http://www.altocomisionadoparalapaz.gov.co/procesos-yconversaciones/Documentos\%20compartidos/24-11-2016NuevoAcuerdoFinal.pdf

Darío Fajardo, Tierra, poder político y reformas agraria y rural. Bogotá, Antropos, 2002, https://problemasrurales.files.wordpress.com/2008/12/tierra-poder-y-reforma-dario-fajardo2002.pdf

Departamento Nacional de Planeación, El plan que le cambió la cara al país: DNP. Bogotá, Departamento Nacional de Planeación, 2016, https://planeacionnacional- 
my.sharepoint.com/personal/prensadnp dnp gov co/ layouts/15/WopiFrame.aspx?guestaccesstoke

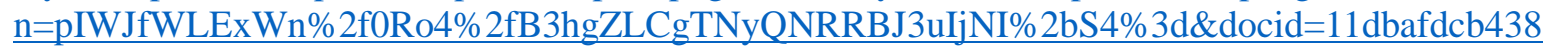
$\underline{54 \mathrm{e} 27820 \mathrm{fdae} 1 \mathrm{f} 29 \mathrm{~b} 79 \mathrm{~b} 1 \& \text { action }=\text { view }}$

Dinero, Así va la deuda del Gobierno en 2017, Dinero, 17 de julio de 2017, http://www.dinero.com/economia/articulo/deuda-del-gobierno-colombia-2017/247571

El Tiempo, El 64\% de hogares rurales no cuentan con acceso a la tierra, El Tiempo, 26 de noviembre de 2016, http://www.eltiempo.com/economia/sectores/desigualdad-en-la-propiedad-dela-tierra-en-colombia-32186

Oxfam Internacional, Desterrado: tierra, poder y desigualdad en América Latina, 2016, https://www.oxfam.org/sites/www.oxfam.org/files/file_attachments/desterrados-ejecutivo-es-29novweb_0.pdf

\section{Leyes}

Colombia, Ley 200 de 1936, sobre régimen de tierras. 